\title{
Culturally-consistent diet among individuals of Mexican descent at the US-Mexico border is associated with sleep duration and snoring
}

Sadia B. Ghani ${ }^{1 *}$, Krishna Taneja ${ }^{1}$, Chloe C. A. Wills ${ }^{1}$, Andrew S. Tubbs', Marcos E. Delgadillo ${ }^{1}$, Dora Valencia ${ }^{1}$, Mohamed Halane', William D. S. Killgore ${ }^{3}$ and Michael A. Grandner ${ }^{1}$

\begin{abstract}
Background: Existing studies show that consuming food consistent with one's culture reduces cardiometabolic risk. However, few studies have assessed whether these dietary choices influence sleep health. Accordingly, this study assessed how Mexican food consumption by individuals of Mexican descent residing at the US-Mexico border, was associated with various measures of sleep, after accounting for acculturation.
\end{abstract}

Methods: Data were provided by 100 adults between the ages of 18-60, in the city of Nogales, AZ. Questionnaires were provided in either Spanish or English. Acculturation was assessed with the Acculturation Scale for MexicanAmericans (ARSMA-II), with an additional question, asking how often "my family cooks Mexican foods." Frequency of cooking Mexican food was coded as either "yes" or "no." Sleep was assessed, using validated measures that include the Insomnia Severity Index (ISI), the Epworth Sleepiness Scale (ESS), the Pittsburgh Sleep Quality Index (PSQI), and sleep duration with the item "how many hours of actual sleep did you get at night?" Regression models estimated the associations between sleep health variables as outcomes and consumption of Mexican food as the independent variable. Covariates included age, sex, and acculturation scores. Parental education level was also included, as an indicator of childhood socioeconomic status and since food culture likely involves parents.

Result: We found that among individuals who identified as Mexican-Americans who consumed culturallyconsistent foods, was associated with, on average, 1.41 more hours of sleep $(95 \% \mathrm{Cl} 0.19,2.62 ; p=0.024)$ and were less likely to report snoring (OR: $0.25 ; 95 \% \mathrm{Cl} 0.07,0.93 ; p=0.039)$. Consuming Mexican food was not associated with sleep quality, insomnia severity or sleepiness.

\footnotetext{
* Correspondence: sghani@email.arizona.edu

'Department of Psychiatry, Sleep and Health Research Program, University of Arizona, 1501 N Campbell Rd Suite 7326, Tucson, AZ 85724-5002, USA

Full list of author information is available at the end of the article
}

(c) The Author(s). 2021 Open Access This article is licensed under a Creative Commons Attribution 4.0 International License, which permits use, sharing, adaptation, distribution and reproduction in any medium or format, as long as you give appropriate credit to the original author(s) and the source, provide a link to the Creative Commons licence, and indicate if changes were made. The images or other third party material in this article are included in the article's Creative Commons licence, unless indicated otherwise in a credit line to the material. If material is not included in the article's Creative Commons licence and your intended use is not permitted by statutory regulation or exceeds the permitted use, you will need to obtain permission directly from the copyright holder. To view a copy of this licence, visit http://creativecommons.org/licenses/by/4.0/ The Creative Commons Public Domain Dedication waiver (http://creativecommons.org/publicdomain/zero/1.0/) applies to the data made available in this article, unless otherwise stated in a credit line to the data. 
Conclusion: Individuals of Mexican descent residing at the US-Mexico border who regularly consumed Mexican food, reported more sleep and less snoring. Mexican acculturation has been shown previously to improve sleep health. This is likely due to consumption of a culturally- consistent diet. Future studies should examine the role of acculturation in sleep health, dietary choices, and subsequent cardiometabolic risk.

Keywords: Sleep duration, Cultural food, Sleep health, Snoring, Border health disparities

\section{Introduction}

Previous studies have shown that long and short sleep duration is related to dietary nutrient and timing of intake $[1-5]$. Laboratory studies show that alterations in sleep duration and timing of sleep can result in acute changes to dietary intake patterns, including increased daily caloric intake and meal consumption and reduced energy expenditure [6, 7]. Additional work at the community and population level shows that insufficient sleep duration and/or poor sleep quality are associated with unhealthy food intake, including preferring fatty foods, skipping breakfast, snacking, eating outside the home $[1,3,8,9]$, weight gain [10], and incident obesity $[11,12]$, even after adjusting for BMI and physical activity [3]. While informative, prior studies have not specifically addressed how sleep may influence dietary intake in racial/ethnic minorities, particularly Hispanic/Latino individuals.

Obesity is a rising public health epidemic in the United States (US) [13, 14], and rates of obesity are disproportionately higher in Hispanic individuals $[15,16]$, particularly Mexican-Americans [13]. Hispanics/Latinos are now the largest minority group in the US and Mexican-Americans are the largest sub-group within this population [17], so addressing this disparity should include a focus on sleep health, as it relates to food intake. Sleep disparities have been documented in Hispanics/Latinos as well [18, 19], and emerging evidence suggests that habitual sleep is decreasing among Mexican-Americans at more than twice the rate seen in Non-Hispanic Whites [20]. A better understanding of the relationships between sleep and food intake in Mexican-Americans may help address these disparities.

Mexican-Americans exhibit more unhealthy cardiometabolic outcomes when they adopt an "Americanized" dietary pattern, including weight gain [21], obesity [22, 23], and risk of diabetes [23]. These outcomes are also associated with poor sleep in this population [13, 16, 18, 24-29], such that adopting an "Americanized" diet may be related to poor sleep. Alternatively, poor sleep may influence poor dietary choices $[1,2,6,30]$ and acculturation may contribute to this relationship [31-33]. Acculturation towards an "Americanized" mindset is associated with a greater likelihood of insufficient and/or poor-quality sleep [31-35], while less acculturation may protect against poor sleep and negative health behaviors [31, 32]. Although eating more culturally-consistent food is associated with better health outcomes in this population [36], the specific relationships between sleep and culturally-consistent diets have not been explored, especially in the Hispanic/Latino population. If eating culturally-consistent foods is associated with better sleep quality independent of overall acculturation, then interventions targeting sleep and culturally-consistent diets may reduce cardiometabolic disease in the Mexican-American population.

Accordingly, the present study evaluated whether habitual consumption of Mexican food by individuals of Mexican descent living at the US-Mexico border was associated with sleep duration, sleep quality, daytime sleepiness and snoring, independent of acculturation. The hypotheses were that individuals from this group who do not consume these foods would report (1) shorter habitual sleep duration, (2) worse sleep quality, (3) more daytime sleepiness, and (4) more snoring.

\section{Methods \\ Participants}

A sample of $N=100$ adults between the ages 18-60, of Mexican descent living in Nogales, AZ were surveyed for this study. Recruitment involved in-person solicitations, flyers, and social media posts in both English and Spanish. Participants were (1) fluent in English or Spanish, (2) over the age of 18 years, and (3) identified as Mexican-American or Mexican. Exclusion criteria included medical conditions or serious mental illnesses that affected the participant's ability to provide consent or participate. Surveys were distributed in the participants preferred language, via a tablet and administered by a fully bilingual research staff during late summer and early fall of 2017. The study protocol was approved by the University of Arizona IRB (protocol \# 1608763580) and informed consent was obtained prior to participation. All methods were carried out in accordance to relevant regulations and guidelines.

\section{Measures}

The Pittsburgh Sleep Quality Index (PSQI) [37] assessed overall sleep quality. The PSQI is well validated and frequently used screening tool, assessing several domains of sleep and differentiates "good" and "poor" sleepers. A summed total score greater than 5 is indicative of worse 
sleep quality [37]. The PSQI has been previously used in this population [31].

The Insomnia Severity Index (ISI) [38] assessed both daytime and nighttime components of insomnia. It is a well-recognized and validated index and is used as a standard outcome measure in studies related to insomnia [38]. It is available in several languages including Spanish [39], and has been previously used in this population [31].

Sleep duration was assessed by asking participants: "How many hours of actual sleep did you get at night?" (This may be different than the number of hours you spend in bed)." Responses were recorded in 15-min increments.

Daytime sleepiness was assessed using the Epworth Sleepiness Scale (ESS) [40], which is validated in clinical and research settings [41], is available in Spanish [42], and has been previously used in this population [31]. The ESS measures the propensity to fall asleep in a range of situations with higher scores indicating increased daytime sleepiness [40].

Participants were asked to state how often they snored with options including "never," "rarely," "sometimes," "often," or "always."

Acculturation was assessed with the Acculturation Rating Scale for Mexican Americans II (ARSMA-II) [43]. This scale includes two independent subscales for "Mexican" and "Anglo" acculturation, and it includes 13 questions on the Anglo Orientation Subscale and 17 questions on the Mexican Orientation Subscale. Respondents answer each question on a Likert scale ranging from 0 ("not at all") to 4 ("extremely often or almost always"), and responses are averaged within each subscale. The higher the value on each scale indicates the higher acculturation of either Mexican and/or Anglo acculturation.

The degree to which individuals report eating culturally-consistent food was assessed with the survey item, "My family cooks Mexican Foods." Responses were coded as "yes" if individuals answered "very often" or "almost always" and "no" if individuals answered "not at all," "not very often," or "moderately."

Finally, age, sex, acculturation and parental education levels were included as covariates since parental education is an indicator of childhood socioeconomic status and because food culture likely involves parental influence.

\section{Translation of measures into Spanish}

Wherever possible, previously validated Spanish versions of questionnaires were used. English-only measures were translated using Guideline-based translation procedures $[44,45]$. Specific translation procedures are described in detail elsewhere [31], including some textual changes to the ISI to accommodate regional language preferences [31]. Ultimately, all questionnaires were available in either English or Spanish and participants completed these measures in the language of their choice.

\section{Statistical analyses}

The study outcomes were sleep duration (hours), sleep quality (PSQI score), insomnia severity (ISI score), daytime sleepiness (ESS score), and snoring. All variables were continuous except for snoring which was treated as an ordinal variable. The independent variable was consumption of Mexican food (yes/no), and sex, age, parental education, and acculturation were included as covariates. Linear and ordinal logistic regression models evaluated the relationships between consumption of Mexican food and each sleep variable. A likelihood ratio test comparing ordinal and binomial logistic regression models found no significant differences $(p=0.3)$, suggesting that the ordinal approach was appropriate. Results are reported as unstandardized regression coefficients (B) for linear variables and ordinal Odds Ratios (OR) for snoring, with 95\% confidence intervals (CI). All analyses were performed in STATA 14.2 (STATACORP, College Station, TX).

\section{Results}

Table 1 reports the characteristics of the sample. Most respondents $(N=87)$ reported that their family regularly prepared Mexican food. The mean age was 36.5 years $(\mathrm{SD}=19.1)$, and the sample was $47 \%$ female. Mean Mexican acculturation was $2.90(\mathrm{SD}=0.75)$ and mean Anglo acculturation was 1.94 $(\mathrm{SD}=0.94)$, indicating participants had stronger orientation toward Mexican acculturation. A plurality of respondents reported a parental education less than a high school. Mean sleep duration was $6.06 \mathrm{~h}(\mathrm{SD}=1.75)$ and the mean PSQI score was $7.73(\mathrm{SD}=3.47)$ indicating poor sleep quality. The mean ISI score was $9.14 \quad(\mathrm{SD}=4.20)$, which falls in the range of subclinical insomnia, and the mean ESS score was $6.36(\mathrm{SD}=4.33)$, which indicates typical levels of sleepiness. Finally, $41 \%$ of respondents reported "never" snoring while, $13 \%$ reported "always" snoring. Those who consistently ate Mexican food reported higher levels of Mexican acculturation $(p=0.0004)$ and longer sleep durations $(p=0.0377)$ than those who did not. There were no other significant differences between groups.

Table 2 reports the associations between consumption of Mexican food and sleep related variables. In adjusted analyses, those whose family regularly made Mexican food reported $1.41 \mathrm{~h}$ of sleep (95\% CI: 0.19, 2.62, $p=$ 0.024 ), and were less likely to report snoring (OR: 0.25 , $95 \%$ CI: $0.07,0.93, p=0.039$ ). No statistically significant differences were seen for sleep quality, insomnia severity, or daytime sleepiness. 
Table 1 Characteristics of the N=100 Individuals; Late Summer/Early Fall 2017; Nogales AZ

\begin{tabular}{|c|c|c|c|c|}
\hline \multirow[t]{2}{*}{${ }^{\text {a} V a r i a b l e ~}$} & \multirow{2}{*}{$\begin{array}{l}\text { Complete } \\
\text { Sample } \\
(N=100)\end{array}$} & \multicolumn{3}{|c|}{ Stratified by Frequent Consumption of Culturally-Consistent Food } \\
\hline & & No $(N=13)$ & Yes $(N=87)$ & $\mathrm{a}, \mathrm{b} p$ \\
\hline Age (Years) & $36.50 \pm 19.10$ & $30.34 \pm 23.07$ & $37.45 \pm 18.36$ & 0.3050 \\
\hline Sex & & & & 0.9480 \\
\hline Male & 53.00 & 53.85 & 52.87 & \\
\hline Female & 47.00 & 46.15 & 47.13 & \\
\hline \multicolumn{5}{|l|}{ Acculturation } \\
\hline Mexican & $2.90 \pm 0.75$ & $1.79 \pm 0.96$ & $3.06 \pm 0.55$ & 0.0004 \\
\hline Anglo & $1.94 \pm 0.94$ & $2.03 \pm 1.00$ & $1.93 \pm 0.93$ & 0.7449 \\
\hline Mother's Education & & & & 0.7924 \\
\hline Less Than High School & 42.00 & 30.80 & 43.70 & \\
\hline High School & 13.00 & 15.40 & 12.60 & \\
\hline Some College & 23.0 & 23.10 & 23.00 & \\
\hline College & 22.0 & 30.80 & 20.70 & \\
\hline Father's Education & & & & 0.3120 \\
\hline Less than High School & 39.00 & 23.10 & 41.40 & \\
\hline High School & 18.00 & 30.80 & 16.10 & \\
\hline Some College & 20.00 & 30.80 & 18.40 & \\
\hline College & 23.00 & 15.40 & 24.10 & \\
\hline PSQI Sleep Duration (Hours) & $6.06 \pm 1.75$ & $4.83 \pm 2.14$ & $6.24 \pm 1.62$ & 0.0377 \\
\hline PSQI Total Score & $7.73 \pm 3.47$ & $7.69 \pm 4.42$ & $7.74 \pm 3.34$ & 0.9734 \\
\hline ISI Score & $9.14 \pm 4.20$ & $8.08 \pm 4.52$ & $9.30 \pm 4.16$ & 0.3726 \\
\hline ESS Score & $6.36 \pm 4.33$ & $7.00 \pm 5.58$ & $6.26 \pm 4.14$ & 0.6549 \\
\hline Snoring & & & & 0.0681 \\
\hline Never & 41.00 & 30.80 & 42.50 & \\
\hline Rarely & 18.00 & 15.40 & 18.40 & \\
\hline Sometimes & 19.00 & 15.40 & 19.50 & \\
\hline Often & 9.00 & 30.80 & 5.75 & \\
\hline Always & 13.00 & 7.69 & 13.80 & \\
\hline
\end{tabular}

${ }^{a}$ Values reported as percent or mean \pm standard deviation $(\%$ or $\mathrm{M} \pm \mathrm{SD}$ )

${ }^{\mathrm{b}}$ Tests of significance were either student's t-tests or chi-squared tests

PSQI Pittsburgh Sleep Quality Index, ISI Insomnia Severity Index, ESS Epworth Sleepiness Scale

Table 2 Associations between Frequent Consumption of Mexican Food and Sleep-Related Variables Among Individuals of Mexican Descent; $N=100$; Late Summer/Early Fall 2017; Nogales AZ

\begin{tabular}{|c|c|c|c|c|c|c|c|c|c|c|c|c|c|c|c|}
\hline \multirow{2}{*}{$\begin{array}{l}N=100 \\
\text { Mexican Diet }\end{array}$} & \multicolumn{3}{|c|}{$\begin{array}{l}\text { Sleep Duration } \\
\text { (hours) }\end{array}$} & \multicolumn{3}{|c|}{$\begin{array}{l}\text { Sleep Quality } \\
\text { (PSQI score) }\end{array}$} & \multicolumn{3}{|c|}{$\begin{array}{l}\text { Insomnia Severity } \\
\text { (ISI score) }\end{array}$} & \multicolumn{3}{|c|}{$\begin{array}{l}\text { Sleepiness } \\
\text { (ESS score) }\end{array}$} & \multicolumn{3}{|c|}{ Snoring } \\
\hline & B & $95 \% \mathrm{Cl}$ & $p$ & B & $95 \% \mathrm{Cl}$ & $p$ & B & $95 \% \mathrm{Cl}$ & $p$ & B & $95 \% \mathrm{Cl}$ & $p$ & OR & $95 \% \mathrm{Cl}$ & $p$ \\
\hline No & \multicolumn{3}{|c|}{ Reference } & \multicolumn{3}{|c|}{ Reference } & \multicolumn{3}{|c|}{ Reference } & \multicolumn{3}{|c|}{ Reference } & \multicolumn{3}{|c|}{ Reference } \\
\hline Yes & 1.4 & $0.19,2.62$ & 0.0240 & 0.11 & $-2.27,2.48$ & 0.9290 & 1.93 & $-0.95,4.81$ & 0.1860 & -0.89 & $-4.08,2.31$ & 0.5810 & 0.25 & $0.07,0.93$ & 0.0390 \\
\hline
\end{tabular}

Models adjusted for age, sex, maternal education, paternal education, Mexican acculturation, and Anglo acculturation

OR Odds Ratio, CI Confidence Interval, PSOI Pittsburgh Sleep Quality Index, ISI Insomnia Severity Index, ESS Epworth Sleepiness Scale

$P<0.05$ considered statistically significant 


\section{Discussion}

The present study explored how a culturally-consistent diet related to sleep duration, insomnia severity, daytime sleepiness, sleep quality, and snoring in adults of Mexican descent at the US-Mexico border. Overall, a culturally-consistent diet was associated with longer sleep duration and decreased likelihood of snoring, but was not associated with daytime sleepiness, insomnia, or sleep quality.

The main finding was that adults of Mexican descent who primarily ate Mexican food reported 1.41 more hours of sleep compared to those who did not eat Mexican food. Social and cultural factors contribute to the determinants of sleep health [46, 47], and food choice represents one cultural element which has clear health implications $[48,49]$. These findings support previous work showing that culturally traditional diets (e.g. Mediterranean, Lebanese, Nordic, and Okinawan diet) lead to better health outcomes [50-54], possibly because of the large amounts of plant-based foods, vegetables, and fruits, and the low amounts of animal-based foods (e.g. red meat), fewer additives, and less refined sugars [50-54]. Studies show that these diets reduce the risk of hypertension and cardiovascular disease, while the western diet is associated with cardiometabolic risk [55, 56]. Additionally, consumption of traditional Mexican food reduces the risk of pre-diabetes [57] and lowers insulin levels [58], although effects on incident obesity are mixed [59-61]. While few studies have explored sleep and the Mexican diet, sleep is closely related to diet and metabolism generally $[62,63]$ and so the Mexican diet likely has an effect on sleep. Further exploration is necessary to understand the role of culturally-consistent diets on sleep health due to the paucity of available literature. Additionally, the novel findings reported here may guide future sleep health interventions to reduce cardiometabolic disorders and improve health disparities in this population. Future studies should evaluate whether a traditional Mexican diet may improve sleep and other health outcomes in this and other populations.

Acculturation strongly influences food choices because nutrition-related attitudes and behaviors tend to be established early in life and are primarily determined by a combination of cultural, psychosocial and socioeconomic factors [64, 65]. Many aspects of food preparation, purchasing, and eating habits are culturally defined, and individuals may either consciously or unconsciously participate in these activities to preserve traditions and maintain group identity. Acculturation associated with sleep health [31-34] and lower Anglo acculturation may protect against poor sleep quality [18, 19, 34, 35]. Furthermore, greater degree of Anglo acculturation is associated with unhealthy weight gain [22], lower rates of physical activity, higher rates of fast-food consumption [66], and increased rates of alcohol use and smoking [67]. Adapting to western culture may lead to Americanized dietary choices, in turn leading to negative cardiometabolic health outcomes [21-23] and greater likelihood of insufficient sleep and poor sleep quality [31-35]. In this study, although those with higher Mexican acculturation scores were more likely to eat Mexican food, dietary choices are just one part of acculturation. The correlation between Mexican acculturation and eating culturally-consistent food was 0.47 , which is high but does not meet the threshold of meaningful collinearity. Therefore, acculturation was included as a covariate.

Parental educational level was also included as a covariate since food culture involves parental influence. Parental socioeconomic status, which refers to parent's income, employment status and level of education, is a multifactorial concept of importance for growth, development, health outcomes and education of children $[68,69]$. Socioeconomic status is a good predictor of dietary habits and quality of sleep [70-72], and may contribute to food-related practices [69]. Because parental education level likely influenced subjects' dietary choices and sleep quality, parental education level was included as a covariate.

Physiological, environmental, and behavioral factors may offer some insight for the association between sleep and diet [63, 73-77], perhaps through changes in eating behaviors and patterns. The effects reported here likely reflect environmental and social factors (e.g., time constraints, work schedules, not preparing home meals). In Nogales specifically, most "non-Mexican" food outlets include fast food and quick-service restaurants, so infrequent consumption of Mexican food may reflect tendencies towards these options. Beyond their apparent lack of healthiness, frequent consumption of fast food is associated with lower levels of healthy behaviors and increased financial and time-related constrains on food choices. Therefore, the observed relationship between Mexican diet and sleep duration may reflect these socioeconomic pressures in addition to any biological mechanisms affected by the food itself. In other words, individuals who did not consistently eat Mexican food at home may have made more unhealthy food choices in general because of non-food-related demands. Thus, the relationship between sleep duration and diet may reflect a regional lack of variety in food options and/or other demands that are related to sleep duration. Unfortunately, specific eating habits were not assessed in this study, so future studies should evaluate environmental factors that may influence eating habits.

While food type and variety are known to affect sleep $[1,30,78,79]$, this study did not collect information on actual foods eaten or what foods were considered 
culturally-consistent by survey respondents. Mexican food culture is rich and is known to be protective against cardiometabolic disorders [50-54, 57-61], but there are limited data examining the relationship between Mexican food and sleep. Therefore, future work on sleep and diet should measure specific dietary data using a standardized food frequency questionnaire. Additional information on timing and type of food consumption on weekdays versus weekends would also be informative given the known associations of meal timing with sleep quality and duration [80-82] and since weekday stressors may be differ from weekend stressors.

Lastly, consuming culturally-consistent food was associated with a decreased likelihood of snoring. Snoring is associated with obstructive sleep apnea and the rates of sleep disordered breathing among individuals of Mexican descent is substantial. In a recent study by $\mathrm{Li}$ and colleagues [83], sleep disordered breathing was associated with $54 \%$ increased likelihood of hypertension and 33\% increased likelihood of diabetes among the U.S. Hispanic/Latino population [24, 83]. This has important implications as sleep disorders are underrepresented, underreported, and undertreated among Hispanic/Latino populations. Thus, consuming culturally-consistent foods may provide a modifiable avenue for intervention for cardiometabolic disease prevention in this population.

\section{Strengths}

This study has several strengths. The use of the ARSMA [43] quantified acculturation more comprehensively than the use of single proxy items (e.g. language immigration status), and the use of both Mexican and Anglo subscales provided a more complete understanding of participants' acculturation. Another strength is that participants were recruited from the US-Mexico border in Arizona, a region which is rural and understudied compared to the urban population used in typical epidemiological research. Lastly, this study provided much needed information regarding border health disparities, particularly in sleep among individuals of Mexican descent.

\section{Limitations}

There are also a few limitations worth mentioning. The cross-sectional study design precludes causal claims, so a longitudinal replication of this study could clarify the association found in this study. Also, despite being one of the largest studies to assess culturally-consistent diet and sleep, the present sample may be underpowered, resulting in unstable effects and wide confidence intervals. However, the non-significant findings has $p$ values that were much greater than 0.05 , suggesting small changes in the sample size would not impact the outcome much. Nonetheless, replication with a larger sample would strengthen these findings and could explore the influence of confounders, mediators/moderators and other unaddressed factors. Additionally, the use of self-report data means these findings are vulnerable to recall and reporting biases. Finally, sleep is related to a wide range of social, behavioral, and environmental factors, and the relatively small sample used here limited the number of covariates to only those deemed necessary. For this reason, health-related variables such as Body Mass Index, history of illnesses, medication use, and physical activity were not included because these factors are so closely related to both sleep and diet that they would over-control the regression models and preclude reasonable inferences. Future studies should consider assessing how these factors may contribute to sleep and dietary choices.

\section{Conclusion and future directions}

The present study explored the relationship between culturally-consistent diet and its association with sleep duration, insomnia severity, daytime sleepiness, sleep quality, and snoring among adults of Mexican descent at the US-Mexico border. The primary findings were that consuming a culturally-consistent diet was associated with longer sleep duration and decreased likelihood of snoring, while there was no association with daytime sleepiness, insomnia, or sleep quality. Future studies should examine environmental, behavioral, and psychosocial factors that may influence these relationships, investigate potential protective factors stemming from cultural influences in the community, and identify possible modifiable strategies that may help prevent these risks.

\section{Abbreviations}

ARSMA-II: The Acculturation Rating Scale for Mexican-Americans II; ESS: Epworth Sleepiness Scale; ISI: Insomnia Severity Scale; PSQI: Pittsburgh Sleep Quality Index; AOS: Anglo-Orientation Scale; MOS: Mexican-Orientation Scale

\section{Acknowledgments \\ I would like to thank Ana Liza for her insightful contribution to this manuscript. This work was supported by T32HL007249, K23HL110216, R01DA051321, R01MD011600, and a grant from the University of Arizona Health Sciences.}

Authors' contributions

All listed authors contributed to this work. Conceptualization, WDSK, MAG. Methodology, MED, MAG, WDSK. Formal Analysis, MAG. Resources, MED, MAG. Data Curation, MED, CCAW, SBG, AST. Writing-Original Draft Preparation, SBG, MAG, CCAW. Writing-Review \& Editing, SBG, CCAW, KT, AST, DV MH, MAG. Project Administration, MED, MAG. Funding Acquisition, SBG, MAG. All authors approved the final manuscript.

\section{Funding}

I am reporting that MAG received grants from Jazz Pharmaceuticals and Kemin Foods, and consulting from Fitbit, Natrol, Merck, Casper, SPV, Merck, Sunovion, University of Maryland, and New York University. The sponsors had no role in the design, execution, interpretation, or writing of the study. 


\section{Availability of data and materials}

Not Applicable.

\section{Declarations}

\section{Ethics approval and consent to participate}

This study was approved by the University of Arizona IRB (protocol \# 1608763580) and informed consent was obtained prior to participation.

\section{Consent for publication}

Not Applicable.

\section{Competing interests}

Not Applicable.

\section{Author details}

'Department of Psychiatry, Sleep and Health Research Program, University of Arizona, 1501 N Campbell Rd Suite 7326, Tucson, AZ 85724-5002, USA. ${ }^{2}$ Medical University of the Americas, Nevis, Saint Kitts And Nevis. ${ }^{3}$ Department of Psychiatry, Social, Cognitive, and Affective Neuroscience (SCAN) Lab, University of Arizona, 1501 N Campbell Rd Suite 7303B, Tucson, AZ 85724, USA.

Received: 7 March 2021 Accepted: 24 June 2021

Published online: 23 August 2021

\section{References}

1. Grandner MA, Jackson N, Gerstner JR, Knutson KL. Dietary nutrients associated with short and long sleep duration. Data from a nationally representative sample. Appetite. 2013;64:71-80. https://doi.org/10.1016/j.a ppet.2013.01.004.

2. Grandner MA, Jackson N, Gerstner JR, Knutson KL. Sleep symptoms associated with intake of specific dietary nutrients. J Sleep Res. 2014;23(1): 22-34. https://doi.org/10.1111/jsr.12084

3. Grandner MA, Kripke DF, Naidoo N, Langer RD. Relationships among dietary nutrients and subjective sleep, objective sleep, and napping in women. Sleep Med. 2010;11(2):180-4. https://doi.org/10.1016/j.sleep.2009.07.014.

4. Sato-Mito N, Sasaki S, Murakami K, Okubo H, Takahashi Y, Shibata S, et al. The midpoint of sleep is associated with dietary intake and dietary behavior among young Japanese women. Sleep Med. 2011;12(3):289-94. https://doi. org/10.1016/j.sleep.2010.09.012

5. Sato-Mito N, Shibata S, Sasaki S, Sato K. Dietary intake is associated with human chronotype as assessed by both morningness-eveningness score and preferred midpoint of sleep in young Japanese women. Int J Food Sci Nutr. 2011;62(5):525-32. https://doi.org/10.3109/09637486.2011.560563.

6. Spaeth AM, Dinges DF, Goel N. Effects of experimental sleep restriction on weight gain, caloric intake, and meal timing in healthy adults. Sleep. 2013; 36(7):981-90. https://doi.org/10.5665/sleep.2792.

7. Markwald RR, Melanson EL, Smith MR, Higgins J, Perreault L, Eckel RH, et al. Impact of insufficient sleep on total daily energy expenditure, food intake, and weight gain. Proc Natl Acad Sci U S A. 2013;110(14):5695-700. https:// doi.org/10.1073/pnas.1216951110.

8. Imaki M, Hatanaka Y, Ogawa Y, Yoshida Y, Tanada S. An epidemiological study on relationship between the hours of sleep and life style factors in Japanese factory workers. J Physiol Anthropol Appl Hum Sci. 2002;21(2): 115-20. https://doi.org/10.2114/jpa.21.115

9. Nishiura $\mathrm{C}$, Hashimoto $\mathrm{H}$. A 4-year study of the association between short sleep duration and change in body mass index in Japanese male workers. J Epidemiol. 2010;20(5):385-90. https://doi.org/10.2188/jea.JE20100019.

10. Patel SR, Hu FB. Short sleep duration and weight gain: a systematic review. Obesity (Silver Spring). 2008;16(3):643-53. https://doi.org/10.1038/oby.2 007.118 .

11. Nielsen LS, Danielsen KV, Sorensen TI. Short sleep duration as a possible cause of obesity: critical analysis of the epidemiological evidence. Obes Rev. 2011;12(2):78-92. https://doi.org/10.1111/j.1467-789X.2010.00724.X.

12. Tan X, Chapman CD, Cedernaes J, Benedict C. Association between long sleep duration and increased risk of obesity and type 2 diabetes: A review of possible mechanisms. Sleep Med Rev. 2018;40:127-34. https://doi.org/1 0.1016/j.smrv.2017.11.001
13. Mozumdar A, Liguori G. Persistent increase of prevalence of metabolic syndrome among U.S. adults: NHANES III to NHANES 1999-2006. Diabetes Care. 2011;34(1):216-9. https://doi.org/10.2337/dc10-0879.

14. Buxton OM, Marcelli E. Short and long sleep are positively associated with obesity, diabetes, hypertension, and cardiovascular disease among adults in the United States. Soc Sci Med. 2010;71(5):1027-36. https://doi.org/10.1016/j. socscimed.2010.05.041.

15. Kaplan RC, Aviles-Santa ML, Parrinello CM, Hanna DB, Jung M, Castaneda SF, et al. Body mass index, sex, and cardiovascular disease risk factors among Hispanic/Latino adults: Hispanic community health study/study of Latinos. J Am Heart Assoc. 2014;3(4):e000923. https://doi.org/10.1161/JAHA.114. 000923.

16. Daviglus ML, Talavera GA, Aviles-Santa ML, Allison M, Cai J, Criqui MH, et al. Prevalence of major cardiovascular risk factors and cardiovascular diseases among Hispanic/Latino individuals of diverse backgrounds in the United States. JAMA. 2012;308(17):1775-84. https://doi.org/10.1001/ja ma.2012.14517.

17. Census Bureau US. American community survey 1-year estimates. Washington, DC: US Census Bureau; 2019. p. 2019.

18. Grandner MA, Petrov ME, Rattanaumpawan P, Jackson N, Platt A, Patel NP Sleep symptoms, race/ethnicity, and socioeconomic position. J Clin Sleep Med. 2013;9(9):897-905; A-D.

19. Whinnery J, Jackson N, Rattanaumpawan P, Grandner MA. Short and long sleep duration associated with race/ethnicity, sociodemographics, and socioeconomic position. Sleep. 2014;37(3):601-11. https://doi.org/10.5665/ sleep.3508.

20. Sheehan CM, Frochen SE, Walsemann KM, Ailshire JA. Are U.S. adults reporting less sleep?: Findings from sleep duration trends in the National Health Interview Survey, 2004-2017. Sleep. 2019;42(2):zsy221. https://doi. org/10.1093/sleep/zsy221.

21. Ahluwalia IB, Ford ES, Link M, Bolen JC. Acculturation, weight, and weightrelated behaviors among Mexican Americans in the United States. Ethn Dis. 2007;17(4):643-9.

22. Delavari M, Sonderlund AL, Swinburn B, Mellor D, Renzaho A. Acculturation and obesity among migrant populations in high income countries--a systematic review. BMC Public Health. 2013;13(1):458. https://doi.org/10.11 86/1471-2458-13-458.

23. Hazuda HP, Haffner SM, Stern MP, Eifler CW. Effects of acculturation and socioeconomic status on obesity and diabetes in Mexican Americans. The San Antonio heart study. Am J Epidemiol. 1988;128(6):1289-301. https://doi. org/10.1093/oxfordjournals.aje.a115082

24. Ghani SB, Begay TK, Grandner MA. Sleep Disordered Breathing and Insomnia as Cardiometabolic Risk Factors Among US Hispanics/Latinos. Am J Respir Crit Care Med. 2021;203(3):258-86. https://doi.org/10.1164/rccm.202 008-3171ED.

25. Grandner MA, Patel NP, Gehrman PR, Xie D, Sha D, Weaver T, et al. Who gets the best sleep? Ethnic and socioeconomic factors related to sleep complaints. Sleep Med. 2010;11(5):470-8. https://doi.org/10.1016/j.sleep.2 009.10.006.

26. Grandner MA, Seixas A, Shetty S, Shenoy S. Sleep duration and diabetes risk: population trends and potential mechanisms. Curr Diab Rep. 2016;16(11): 106. https://doi.org/10.1007/s11892-016-0805-8.

27. Zizi F, Pandey A, Murrray-Bachmann R, Vincent M, McFarlane S, Ogedegbe $\mathrm{G}$, et al. Race/ethnicity, sleep duration, and diabetes mellitus: analysis of the National Health Interview Survey. Am J Med. 2012;125(2):162-7. https://doi. org/10.1016/j.amjmed.2011.08.020.

28. Mosca M, Aggarwal B. Sleep duration, snoring habits, and cardiovascular disease risk factors in an ethnically diverse population. J Cardiovasc Nurs. 2012;27(3):263-9. https://doi.org/10.1097/JCN.0b013e31821e7ad1.

29. Li JYZ, Qiu H, Wang Y, Jian L, Ji J, Li K. Anxiety and depression among general population in China at the peak of the COVID-19 epidemic. World Psychiatry. 2020;19(2):249-50. https://doi.org/10.1002/wps.20758.

30. St-Onge MP, Mikic A, Pietrolungo CE. Effects of diet on sleep quality. Adv Nutr. 2016;7(5):938-49. https://doi.org/10.3945/an.116.012336.

31. Ghani SB, D, M. E, Granados K, Okuagu AC, Alfonso-Miller P, Buxton OM, et al. Acculturation associated with sleep duration, sleep quality, and sleep disorders at the US-Mexico border. Int J Environ Res Public Health. 2020; 17(19):7138. https://doi.org/10.3390/ijerph17197138.

32. Hale L, Rivero-Fuentes E. Negative acculturation in sleep duration among Mexican immigrants and Mexican Americans. J Immigr Minor Health. 2011; 13(2):402-7. https://doi.org/10.1007/s10903-009-9284-1. 
33. Hale L, Troxel WM, Kravitz HM, Hall MH, Matthews KA. Acculturation and sleep among a multiethnic sample of women: the study of Women's health across the nation (SWAN). Sleep. 2014;37(2):309-17. https://doi.org/10.5665/ sleep.3404.

34. Grandner MA, Khader WS, Warlick CD, Fernandez F. Acculturation and sleep: implications for sleep and health disparities. Sleep. 2019;42(3):zsz059. https:// doi.org/10.1093/sleep/zsz059.

35. Martinez-Miller EE, Prather AA, Robinson WR, Avery CL, Yang YC, Haan MN et al. US acculturation and poor sleep among an intergenerational cohort of adult Latinos in Sacramento, California. Sleep. 2019;42(3):zsy246. https:// doi.org/10.1093/sleep/zsy246.

36. Valerino-Perea $S$, Lara-Castor L, Armstrong MEG, Papadaki A. Definition of the Traditional Mexican Diet and Its Role in Health: A Systematic Review. Nutrients. 2019;11(11):2803. https://doi.org/10.3390/nu11112803.

37. Buysse DJ, Reynolds CF 3rd, Monk TH, Berman SR, Kupfer DJ. The Pittsburgh sleep quality index: a new instrument for psychiatric practice and research. Psychiatry Res. 1989;28(2):193-213. https://doi.org/10.1016/0165-1781 (89)90047-4.

38. Bastien $\mathrm{CH}$, Vallieres $\mathrm{A}$, Morin CM. Validation of the insomnia severity index as an outcome measure for insomnia research. Sleep Med. 2001;2(4):297307. https://doi.org/10.1016/S1389-9457(00)00065-4.

39. Fernandez-Mendoza J, Rodriguez-Munoz A, Vela-Bueno A, OlavarrietaBernardino S, Calhoun SL, Bixler EO, et al. The Spanish version of the insomnia severity index: a confirmatory factor analysis. Sleep Med. 2012; 13(2):207-10. https://doi.org/10.1016/j.sleep.2011.06.019.

40. Johns MW. A new method for measuring daytime sleepiness: the Epworth sleepiness scale. Sleep. 1991;14(6):540-5. https://doi.org/10.1093/sleep/14.6.540.

41. Lapin BR, Bena JF, Walia HK, Moul DE. The Epworth sleepiness scale: validation of one-dimensional factor structure in a large clinical sample. J Clin Sleep Med. 2018;14(8):1293-301. https://doi.org/10.5664/jcsm.7258.

42. Sandoval-Rincon M, Alcala-Lozano R, Herrera-Jimenez I, Jimenez-Genchi A. Validation of the Epworth sleepiness scale in Mexican population. Gac Med Mex. 2013;149(4):409-16.

43. Cuellar I, Arnold B, Maldonado R. Acculturation rating scale for Mexican Americans-II: A revision of the original ARSMA scale. Hisp J Behav Sci. 1995; 17(3):275-304. https://doi.org/10.1177/07399863950173001.

44. Hilton A, Skrutkowski M. Translating instruments into other languages: development and testing processes. Cancer Nurs. 2002;25(1):1-7. https://doi. org/10.1097/00002820-200202000-00001.

45. Van de Vijver FJ, Hambleton RK. Translating tests: some practical guidelines. Eur Psychol. 1996;1(2):89-99. https://doi.org/10.1027/1016-9040.1.2.89.

46. Knutson KL. Sociodemographic and cultural determinants of sleep deficiency: implications for cardiometabolic disease risk. Soc Sci Med. 2013; 79:7-15. https://doi.org/10.1016/j.socscimed.2012.05.002.

47. Giannotti F, Cortesi F. Family and cultural influences on sleep development. Child Adolesc Psychiatr Clin N Am. 2009;18(4):849-61. https://doi.org/10.101 6/j.chc.2009.04.003.

48. Carlos S, De La Fuente-Arrillaga C, Bes-Rastrollo M, Razquin C, Rico-Campa A, Martinez-Gonzalez MA, et al. Mediterranean Diet and Health Outcomes in the SUN Cohort. Nutrients. 2018;10(4):439. https://doi.org/10.3390/nu1004 0439.

49. Donini LM, Serra-Majem L, Bullo M, Gil A, Salas-Salvado J. The Mediterranean diet: culture, health and science. Br J Nutr. 2015;113(Suppl 2):S1-3. https:// doi.org/10.1017/S0007114515001087.

50. Esposito K, Maiorino Ml, Bellastella G, Panagiotakos DB, Giugliano D. Mediterranean diet for type 2 diabetes: cardiometabolic benefits. Endocrine. 2017;56(1):27-32. https://doi.org/10.1007/s12020-016-1018-2.

51. Sofi F, Cesari F, Abbate R, Gensini GF, Casini A. Adherence to Mediterranean diet and health status: meta-analysis. BMJ. 2008;337(sep11 2):a1344. https:// doi.org/10.1136/bmj.a1344.

52. Jomaa L, Hwalla N, Itani L, Chamieh MC, Mehio-Sibai A, Naja F. A Lebanese dietary pattern promotes better diet quality among older adults: findings from a national cross-sectional study. BMC Geriatr. 2016;16(1):85. https://doi. org/10.1186/s12877-016-0258-6.

53. Nouripour FH, N. Nordic diet and cardio-metabolic diseases: A review. Int Nutr Sci. 2019;4(3):105-8.

54. Le Couteur DG, Solon-Biet S, Wahl D, Cogger VC, Willcox BJ, Willcox DC, et al. New horizons: dietary protein, ageing and the Okinawan ratio. Age Ageing. 2016;45(4):443-7. https://doi.org/10.1093/ageing/afw069.

55. Drake I, Sonestedt E, Ericson U, Wallstrom P, Orho-Melander M. A Western dietary pattern is prospectively associated with cardio-metabolic traits and incidence of the metabolic syndrome. Br J Nutr. 2018;119(10):1168-76. https://doi.org/10.1017/S000711451800079X.

56. Odegaard AO, Koh WP, Yuan JM, Gross MD, Pereira MA. Western-style fast food intake and cardiometabolic risk in an eastern country. Circulation. 2012;126(2):182-8. https://doi.org/10.1161/CIRCULATIONAHA.111.084004.

57. Robles-Ordaz MD, Gallegos-Aguilar AC, Urquidez-Romero R, Diaz-Zavala RG, Lavandera-Torres MG, Esparza-Romero J. Prevalence of prediabetes and modifiable factors in an ethnic group of Mexico: the Comcaac project. Public Health Nutr. 2018;21(2):333-8. https://doi.org/10.1017/S1368980017002658.

58. Santiago-Torres M, Kratz M, Lampe JW, Tapsoba Jde D, Breymeyer KL, Levy $L$, et al. Metabolic responses to a traditional Mexican diet compared with a commonly consumed US diet in women of Mexican descent: a randomized crossover feeding trial. Am J Clin Nutr. 2016;103(2):366-74. https://doi.org/1 0.3945/ajcn.115.119016.

59. Carrera PM, Gao X, Tucker KL. A study of dietary patterns in the MexicanAmerican population and their association with obesity. J Am Diet Assoc. 2007;107(10):1735-42. https://doi.org/10.1016/j.jada.2007.07.016.

60. Denova-Gutierrez E, Castanon S, Talavera JO, Gallegos-Carrillo K, Flores M, Dosamantes-Carrasco D, et al. Dietary patterns are associated with metabolic syndrome in an urban Mexican population. J Nutr. 2010;140(10): 1855-63. https://doi.org/10.3945/jn.110.122671.

61. Flores M, Macias N, Rivera M, Lozada A, Barquera S, Rivera-Dommarco J, et al. Dietary patterns in Mexican adults are associated with risk of being overweight or obese. J Nutr. 2010;140(10):1869-73. https://doi.org/10.3945/ jn.110.121533.

62. Altman NG, Izci-Balserak B, Schopfer E, Jackson N, Rattanaumpawan P, Gehrman PR, et al. Sleep duration versus sleep insufficiency as predictors of cardiometabolic health outcomes. Sleep Med. 2012;13(10):1261-70. https:// doi.org/10.1016/j.sleep.2012.08.005.

63. Schmid SM, Hallschmid M, Schultes B. The metabolic burden of sleep loss. Lancet Diabetes Endocrinol. 2015;3(1):52-62. https://doi.org/10.1016/S22138587(14)70012-9.

64. Hochbaum G, Kreuter M. Are there any questions? Health Educ. 1981;12(3): 31-2. https://doi.org/10.1080/00970050.1981.10618152.

65. Crockett SS, LS. Environmental influences on Children's eating. J Nutr Educ. 1995;27(5):235-49. https://doi.org/10.1016/S0022-3182(12)80792-8.

66. Unger JB, Reynolds K, Shakib S, Spruijt-Metz D, Sun P, Johnson CA. Acculturation, physical activity, and fast-food consumption among AsianAmerican and Hispanic adolescents. J Community Health. 2004;29(6):467-81. https://doi.org/10.1007/s10900-004-3395-3.

67. Bethel JW, Schenker MB. Acculturation and smoking patterns among Hispanics: a review. Am J Prev Med. 2005;29(2):143-8. https://doi.org/10.101 6/j.amepre.2005.04.014

68. Cook WK, Tseng W. Associations of Asian ethnicity and parental education with overweight in Asian American children and adolescents: an analysis of 2011-2016 National Health and nutrition examination surveys. Matern Child Health J. 2019;23(4):504-11. https://doi.org/10.1007/s10995-018-2662-3.

69. Loth KA, MacLehose RF, Fulkerson JA, Crow S, Neumark-Sztainer D. Eat this, not that! Parental demographic correlates of food-related parenting practices. Appetite. 2013;60(1):140-7. https://doi.org/10.1016/j.appet.2012.09.019.

70. Cameron AJ, Spence AC, Laws R, Hesketh KD, Lioret S, Campbell KJ. A review of the relationship between socioeconomic position and the earlylife predictors of obesity. Curr Obes Rep. 2015;4(3):350-62. https://doi.org/1 0.1007/s13679-015-0168-5.

71. Grandner MA, Williams NJ, Knutson KL, Roberts D, Jean-Louis G. Sleep disparity, race/ethnicity, and socioeconomic position. Sleep Med. 2016;18:718. https://doi.org/10.1016/j.sleep.2015.01.020.

72. Pampel FC, Denney JT, Krueger PM. Obesity, SES, and economic development: a test of the reversal hypothesis. Soc Sci Med. 2012;74(7): 1073-81. https://doi.org/10.1016/j.socscimed.2011.12.028.

73. Dashti HS, Follis JL, Smith CE, Tanaka T, Cade BE, Gottlieb DJ, et al. Habitual sleep duration is associated with BMI and macronutrient intake and may be modified by CLOCK genetic variants. Am J Clin Nutr. 2015;101(1):135-43. https://doi.org/10.3945/ajen.114.095026.

74. McNeil J, Doucet E, Chaput JP. Inadequate sleep as a contributor to obesity and type 2 diabetes. Can J Diabetes. 2013;37(2):103-8. https://doi.org/10.101 6/j.jcjd.2013.02.060.

75. Moller-Levet CS, Archer SN, Bucca G, Laing EE, Slak A, Kabiljo R, et al. Effects of insufficient sleep on circadian rhythmicity and expression amplitude of the human blood transcriptome. Proc Natl Acad Sci U S A. 2013;110(12): E1132-41. https://doi.org/10.1073/pnas.1217154110. 
76. St-Onge MP, O'Keeffe M, Roberts AL, RoyChoudhury A, Laferrere B. Short sleep duration, glucose dysregulation and hormonal regulation of appetite in men and women. Sleep. 2012;35(11):1503-10. https://doi.org/10.5665/ sleep.2198.

77. Taheri S, Lin L, Austin D, Young T, Mignot E. Short sleep duration is associated with reduced leptin, elevated ghrelin, and increased body mass index. PLoS Med. 2004;1(3):e62. https://doi.org/10.1371/journal.pmed.001 0062.

78. Cespedes EM, Hu FB, Redline S, Rosner B, Gillman MW, Rifas-Shiman SL, et al. Chronic insufficient sleep and diet quality: contributors to childhood obesity. Obesity (Silver Spring). 2016;24(1):184-90. https://doi.org/10.1002/ oby.21196.

79. Peuhkuri K, Sihvola N, Korpela R. Diet promotes sleep duration and quality. Nutr Res. 2012;32(5):309-19. https://doi.org/10.1016/j.nutres.2012.03.009.

80. Chaput JP. Sleep patterns, diet quality and energy balance. Physiol Behav. 2014;134:86-91. https://doi.org/10.1016/j.physbeh.2013.09.006.

81. McHill AW, Phillips AJ, Czeisler CA, Keating L, Yee K, Barger LK, et al. Later circadian timing of food intake is associated with increased body fat. Am J Clin Nutr. 2017;106(5):1213-9. https://doi.org/10.3945/ajcn.117.161588.

82. St-Onge MP, Pizinger T, Kovtun K, RoyChoudhury A. Sleep and meal timing influence food intake and its hormonal regulation in healthy adults with overweight/obesity. Eur J Clin Nutr. 2019;72(Suppl 1):76-82. https://doi.org/1 0.1038/s41430-018-0312-x.

83. Correct citation is Li X, Sotres-Alvarez D, Gallo LC, Ramos AR, Aviles-Santa L, Perreira KM, et al. Associations of Sleep Disordered Breathing andlnsomnia with Incident Hypertension and Diabetes: The Hispanic Community Health Study/Study of Latinos. Am J Respir Crit Care Med.2021;203(3):356-65. https://doi.org/10.1164/rccm.201912-2330oc

\section{Publisher's Note}

Springer Nature remains neutral with regard to jurisdictional claims in published maps and institutional affiliations.

Ready to submit your research? Choose BMC and benefit from:

- fast, convenient online submission

- thorough peer review by experienced researchers in your field

- rapid publication on acceptance

- support for research data, including large and complex data types

- gold Open Access which fosters wider collaboration and increased citations

- maximum visibility for your research: over $100 \mathrm{M}$ website views per year

At $\mathrm{BMC}$, research is always in progress.

Learn more biomedcentral.com/submissions 